\title{
A SEPARAÇÃO DOS CONTEÚDOS DAS “LUTAS” DOS "ESPORTES" NA EDUCACCÃO FÍSICA ESCOLAR: NECESSIDADE OU TRADIÇÃO?
}

\author{
Luiz Gustavo Bonatto Rufino \\ Universidade do Estado de São Paulo Júlio de Mesquita Filho, Rio Claro, São Pau- \\ lo, Brasil
}

\section{Suraya Cristina Darido}

Universidade do Estado de São Paulo Júlio de Mesquita Filho, Rio Claro, São Paulo, Brasil

\begin{abstract}
Resumo
Muitas propostas curriculares de Educação Física escolar apresentam as lutas separadas da categoria de esportes. Mas lutas não são esportes? Por que há essa separação? O objetivo desse trabalho foi discutir sobre os possíveis motivos pelos quais as lutas são separadas dos conteúdos dos esportes na esfera da cultura corporal. Para isso, buscou-se por meio de uma revisão de literatura, analisar as concepções de lutas e esportes presentes nas propostas curriculares e em alguns autores da área da Educação Física. Conclui-se que a separação ocorre por diferentes motivos e pode constituir uma maneira de garantir que as lutas sejam efetivamente implementadas nas aulas de Educação Física escolar.
\end{abstract}

Palavras-chave: Lutas - Artes Marciais - Esportes - Educação Física Escolar

\section{Introdução}

s modalidades de lutas, também denominadas de artes marciais,
práticas, cada uma com suas especificidades, regras e normas. Há ain-
da muitos praticantes dessas modalidades. Somente em relação ao
judô, por exemplo, estima-se haver no Brasil cerca de dois milhões de
praticantes (DA COSTA, 2006).

Há também um grande número de espectadores de desenhos animados e filmes, além de muitos consumidores de produtos que abordam as lutas, como videogames, revistas, dvds, camisetas, canais de televisão, dentre outros, assim como nos esportes e outras práticas corporais.

Contudo, as lutas ainda estão afastadas do ambiente escolar e, mesmo sendo defendida por inúmeros autores e propostas curriculares, não são aplicadas de maneira contínua e sistematizada, conforme 
alerta Carreiro (2005). O autor afirma que dentre os conteúdos que podem ser apresentados na Educação Física escolar, as lutas são um dos que encontram maior resistência por parte dos professores, com argumentos como: falta de espaço, falta de material, falta de vestimentas adequadas e associação intrínseca às questões de violência (CARREIRO, 2005).

Eis uma grande divergência encontrada: embora garantida por propostas curriculares e defendida por inúmeros autores, na prática escolar as lutas ainda não aparecem enquanto um conteúdo plenamente ensinado. Por que isso ocorre?

Del'Vecchio e Franchini (2006) consideram que a dificuldade em tratar os conteúdos das lutas na escola deve-se, em grande parte, à formação do profissional de Educação Física que, em muitos casos, frequenta uma graduação deficiente em relação a esses conteúdos, restringindo-se à apenas uma modalidade (como o judô ou a capoeira, por exemplo), ou as vezes sequer havendo a presença desses conteúdos no ensino superior.

Dessa forma, as lutas geralmente são aplicadas apenas (e isso quando são) pelos profissionais que tiveram vivências com esta temática durante suas vidas, independente de terem tido aulas de lutas ou não em sua formação inicial. Há casos também de algumas escolas que oferecem aos alunos modalidades de lutas como judô e karatê como atividade extracurricular, ministradas por ex-praticantes, não integradas ao Projeto Político Pedagógico da escola.

Outro problema é a falta de pesquisas sobre lutas no Brasil, fato evidenciado por Correia e Franchini (2010) ao analisarem 11 periódicos nacionais no período de 1998 até 2008 e constatarem que dos 2561 encontrados, apenas 75 (ou 2,93\%) eram sobre lutas. Os autores encontraram ainda um número muito baixo de artigos que abordassem os aspectos pedagógicos das lutas. A maioria dos artigos encontrados abordou as lutas nas temáticas da fisiologia ou do comportamento motor (CORREIA e FRANCHINI, 2010).

Apesar das dificuldades, é possível tratar a temática das lutas na escola, afinal, estes conteúdos são assegurados por uma série de propostas e autores que as destacam como sendo parte integrante do que se denomina de cultura corporal. Entretanto, surge uma questão para ser analisada, uma vez que todos estes autores e propostas diferenciam as lutas dos esportes.

As lutas não são esportes? Ora, as modalidades apresentadas pela 
mídia, praticadas por inúmeras pessoas, integrantes do seleto grupo de práticas olímpicas, como é o caso do boxe amador, do judô, do wrestling, da esgrima e do taekwondo, não possuem características que nos permitem classificá-las como esportes?

Por que nas definições de cultura corporal há essa diferenciação entre lutas e esportes? Seriam as lutas o mesmo que esportes? Se sim, por que distingui-los? Se não, como diferenciar as lutas dos esportes e, mais ainda, por que no âmbito da cultura corporal é assegurado que as lutas sejam práticas distintas dos demais conteúdos?

Estas indagações são complexas e difíceis de serem respondidas, afinal, as explicações sobre estas diferenças ainda não foram abordadas de maneira sistemática. Assim, por meio de uma revisão de literatura sobre os seguintes temas: a cultura corporal, os esportes e as lutas; um olhar da sociologia do esporte; caracterização esportiva das lutas e, finalmente, lutas: são ou não são esportes, pretendeu-se discutir sobre estas questões, objetivando analisar as possibilidades de se compreender as lutas separadamente dos esportes e seus desdobramentos no universo escolar.

\section{A cultura corporal, os esportes e as lutas}

A seguir, serão apresentadas algumas definições sobre a perspectiva da cultura corporal encontradas em alguns autores e propostas curriculares da área da Educação Física, observando as diferenciações apresentadas com relação aos conteúdos dos esportes e das lutas.

Soares et al. (1992) afirmam que a Educação Física escolar tem como objeto de estudo a reflexão sobre a cultura corporal. Para os autores, essa dinâmica curricular no âmbito da Educação Física tem características bem diferenciadas das da tendência anterior já que:

Busca desenvolver uma reflexão pedagógica sobre o acervo de formas de representação do mundo que o homem tem produzido no decorrer da história, exteriorizadas pela expressão corporal: jogos, danças, lutas, exercícios ginásticos, esporte, malabarismo, contorcionismo, mímica e outros, que podem ser identificados como formas de representação simbólica de realidades vividas pelo homem, historicamente criadas e culturalmente desenvolvidas (SOARES et al., 1992, p. 38, grifo nosso). 
Para os autores, ter a cultura corporal como objeto de estudo e reflexão envolve considerar esse acervo de formas e representações corporais do mundo de extrema importância tanto histórica quanto social, assim, a área da Educação Física deve formular recorte epistemológico próprio, tratando de conteúdos como, por exemplo, as lutas (SOARES et al., 1992).

Ainda segundo estes autores, o homem se apropria da cultura corporal dispondo sua intencionalidade para o lúdico, o artístico, o agonístico, o estético ou outros, que são representações, ideias, conceitos produzidos pela consciência social, denominado por eles de "significações objetivas" (SOARES et al.; 1992, p. 62).

Soares (1996) relata também que, historicamente, a Educação Física ocidental moderna tem ensinado o jogo, a ginástica, as lutas, a dança e os esportes, sendo considerados como "conteúdos clássicos que permaneceram através do tempo transformando inúmeros de seus aspectos, para se afirmar como elementos da cultura, como linguagem singular do homem no tempo" (SOARES, 1996, p. 11, grifo nosso).

Darido e Rangel (2005, p. 34, grifo nosso) compreendem a Educação Física como uma prática pedagógica cuja função é "formar os cidadãos que irão usufruir, partilhar, produzir, reproduzir e transformar as manifestações que caracterizam essa área, tais como: o Jogo, o Esporte, a Dança, a Ginástica e a Luta".

Darido e Souza Júnior (2007, p. 14, grifo nosso) apresentam uma proposta pedagógica na qual compreendem a Educação Física como uma "disciplina curricular voltada a introduzir e integrar o aluno a esfera da cultura corporal, instrumentalizando-os para usufruir de jogos, esportes, danças, lutas e ginásticas".

Betti (2009) também separa as lutas dos esportes, conceituando a Educação Física na escola como:

(...) uma disciplina que tem por finalidade propiciar aos alunos a apropriação crítica da Cultura Corporal de Movimento, visando formar o cidadão que possa usufruir, compartilhar, produzir e transformar as formas culturais do exercício da motricidade humana: jogo, esporte, ginásticas e práticas de aptidão física, dança e atividades rítmicas/ expressivas, lutas/ artes marciais, práticas alternativas (BETTI, 2009, p. 64, grifo nosso). 
Este autor acrescenta ao tema das lutas a expressão artes marciais, embora não os diferencie. Para o presente estudo também não houve a diferenciação destes termos, pois não há consenso quanto à diferenciação ou semelhança dos conceitos de lutas, artes marciais, budo e modalidades esportivas de combate, havendo autores que os diferenciam enquanto que outros os classificam como sinônimos. No entanto, $\mathrm{Ru}-$ fino e Darido (2009) afirmam que:

Mais relevante ainda não é a discussão sobre qual terminologia está mais correta ou deve ser empregada em relação à outra e sim discutir sobre a inserção desses conteúdos, [lutas, artes marciais, modalidades esportivas de combate, etc.], que fazem parte da cultura corporal, nas aulas de Educação Física (RUFINO e DARIDO, 2009, p. 406).

Outra ressalva deve ser feita ao fato de Betti (2009) utilizar o termo "cultura corporal de movimento". Embora haja diferentes terminologias para caracterizar esse acervo de manifestações corporais humanas, como cultura física, cultura corporal, cultura de movimento, cultura corporal de movimento, entre outras, todas caracterizam o lutar como uma das manifestações pertencentes a essa cultura, tendo importância histórica e social. Assim, buscando encontrar adequações sobre a terminologia, optou-se por utilizar a expressão "cultura corporal" conforme o referencial da abordagem crítico-superadora de Soares et al. (1992).

De acordo com os Parâmetros Curriculares Nacionais (PCNS/BRASIL, 1998, p. 28, grifo nosso) a Educação Física tem uma história de pelo menos um século e meio no mundo ocidental moderno, possuindo "uma tradição e um saber-fazer ligados ao jogo, ao esporte, à luta, à dança e à ginástica, e, a partir deles, tem buscado a formulação de um recorte epistemológico próprio".

Algumas propostas curriculares também distinguem o conteúdo das lutas dos esportes. Conforme descrito na Proposta Curricular do Estado de São Paulo para a área da Educação Física, a Educação Física escolar deve tratar pedagogicamente de conteúdos culturais relacionados ao movimentar-se humano, "porque o ser humano, ao longo de sua evolução de milhões de anos, foi construindo certos conhecimentos ligados ao uso do corpo e ao seu movimentar-se" (SÃO PAULO, 2008, p. 42). De acordo com esta proposta: "a Educação Física trata 
da cultura relacionada aos aspectos corporais, que se expressa de diversas formas, dentre as quais os jogos, a ginástica, as danças e atividades rítmicas, as lutas e os esportes" (SÃO PAULO, 2008, p. 42, grifo nosso).

A Proposta Curricular do Estado do Rio Grande do Sul relacionada à área da Educação Física, elaborada para servir de apoio ao professor da rede estadual de ensino daquele estado, descreve que: “(...) as práticas esportivas, as ginásticas, as lutas, as atividades lúdicas, as práticas corporais expressivas, entre outras, se firmaram ao longo dos anos como objetos de estudo próprios da Educação Física" (RIO GRANDE DO SUL, 2009, p. 114, grifo nosso).

Dessa forma há a diferenciação dos esportes e das lutas, fato evidenciado inclusive na proposição das atividades, já que conteúdos dos esportes aparecem em quase todas as séries enquanto que os conteúdos das lutas são propostos apenas nas sétimas e oitavas séries (denominadas atualmente de oitavo e nono ano). Além disso, a proposta estima que as lutas sejam tratadas durante somente $8 \%$ do tempo relativo ao ensino dos conteúdos da Educação Física (RIO GRANDE DO SUL, 2009).

É evidente que, nas proposições apresentadas, o conteúdo das lutas diferencia-se dos conteúdos dos esportes, sendo explicitado separadamente como uma das práticas que compõem a cultura corporal, devendo ser abordado nas aulas de Educação Física escolar. Entretanto, para melhor compreender a separação apresentada pelos autores e pelas propostas analisadas, é preciso compreender outros olhares sobre esta distinção. A seguir será abordada algumas considerações acerca da visão da sociologia do esporte para a caracterização conceitual de esportes e, a partir dessa concepção, considerar ou não a possibilidade de classificar as lutas como modalidades esportivas.

\section{Um olhar da sociologia do esporte}

Não será feita uma extensa revisão sobre o conceito de esporte, tanto do ponto de vista histórico, quanto sociológico, pretendendo-se contextualizar, ainda que inicialmente, as origens e relações entre os esportes e as lutas. A origem dos esportes modernos diferencia-se das origens do conceito mais amplo de lutar relacionado à busca pela sobrevivência, historicamente envolvido com os seres humanos desde o período da pré-história, como afirma Ramos (1982, p. 16): “o homem 
pré-histórico, no primórdio do seu primitivismo, tinha sua vida cotidiana assinalada, sobretudo, por duas grandes preocupações: atacar e defender-se".

Segundo Virgílio (1994), os primeiros indícios da utilização pelo homem de algumas formas primitivas de luta individual e sem armas datam de três a quatro mil anos antes de Cristo. Antes disso, entretanto, o conhecimento se perde no tempo, mas "a própria sobrevivência do homem supõe alguma forma de luta" (VIRGÍLIO, 1994, p. 32).

Ou seja, o ato de lutar é tão antigo quanto a própria história da humanidade. Ao longo do tempo, estas manifestações que foram de sobrevivência e utilitárias, passaram a ser sistematizadas e regulamentadas de acordo com cada sociedade, surgindo diferentes práticas, permeadas por processos históricos repleto de rupturas e descontinuidades.

Esta origem diferencia-se da origem dos esportes modernos. Primeiro, é preciso deixar claro que "esportes" são estes. Elias e Dunning (1992) afirmam que os esportes modernos surgiram na Inglaterra no século XIX. Entretanto, os autores defendem que já no século XVIII se iniciou o que eles denominam de "processo de esportivização" dos passatempos populares (ELIAS e DUNNING, 1992). Ou seja, os conceitos sobre esporte caracterizados a seguir correspondem aos do esporte moderno, originário na Inglaterra do século XIX.

Helal (1990) trás uma importante contribuição para a compreensão do esporte pelo enfoque da sociologia. Inicialmente, este autor diferencia jogo de esporte ao afirmar que eles possuem fronteiras bem demarcadas porque nos esportes há uma organização burocrática mais ampla, eles são organizados em grande escala e situados acima e além dos interesses individuais dos jogadores. "Os esportes possuem ainda os elementos da disputa física e da competição" (HELAL, 1990, p. 28).

O autor afirma também que o esporte é um desdobramento da brincadeira, a mais lúdica das atividades. Entretanto, nos esportes, pode haver a perda do prazer e da autonomia. Existe um prazer lúdico em jogar ou mesmo competir respeitando as regras, porém "a sistematização provocada pela imposição de regras fixas diferencia o esporte da brincadeira, dando-o uma outra roupagem em relação à brincadeira" (HELAL, 1990, p. 31).

Para Helal (1990), o esporte moderno é diferente do esporte de outras épocas por dois motivos: a secularização e a racionalização. A se- 
cularização é o processo pelo qual realidades pertencentes ao domínio religioso, sagrado ou mágico passam a pertencer ao domínio profano, ou seja, "sempre que uma representação racional, científica e técnica substitui uma representação religiosa ou uma explicação pelo sagrado ou pelo divino, há o processo de secularização" (HELAL, 1990, p. 34). O autor lembra que o esporte moderno não possui vínculo religioso, sendo denominado como um evento secular, possibilitando que fosse constituído como uma atividade profissional, altamente organizada e financiada, em muitos casos.

Segundo Helal (1990) a secularização mais recente tomou conta do esporte moderno em quase todo o mundo industrializado, resultando num sentimento generalizado de desencanto. Entretanto, o autor reconhece que ainda persiste uma tendência à sacralização, embora de outra maneira, como se a crescente comercialização dos eventos esportivos absorvessem determinadas características de sacralização. Dessa forma, no esporte moderno, as fronteiras do sagrado e do profano não são bem demarcadas, sendo o esporte, por si só, um domínio extremamente fértil para o surgimento e o desenvolvimento de aspectos sagrados (HELAL, 1990).

Em relação à racionalização, Helal (1990) constata que o esporte moderno procurou paulatinamente eliminar considerações de ordem pessoal, afetiva ou emocional, buscando uma adaptação consciente, exata e eficaz dos meios aos fins pretendidos. As ações passaram a ser governadas por regras bem definidas, calculáveis e racionais, conforme pode ser observado pelo considerável aumento das análises estatísticas, mensurações objetivas, análises táticas, etc. que se tornou a ser a tônica na organização de determinadas modalidades esportivas. No entanto, o autor limita-se ao emprego da racionalização somente na questão da impossibilidade do emprego de raciocínios místicos ou na falta do surgimento de relações e atitudes imprevisíveis (HELAL, 1990), não expandindo a visão sobre esse conceito.

A competição é outra característica dos esportes. Toda competição envolve um "conflito agonístico" entre os participantes. Huizinga (1993) apresentou o conceito de agôn dos gregos para classificar o domínio das competições. Para o autor, tanto o agôn dos gregos quanto as competições em toda a parte do mundo possuem todas as características formais do jogo, pertencendo ao domínio da festa, do lúdico. O agôn é, portanto, uma espécie de jogo que se define por sua função lúdica e pela competição. Tanto os jogos, quanto as competições, as- 
sim como as lutas, as disputas e os combates são agonísticos (antagônicos) para os gregos (HUIZINGA, 1993).

Para Helal (1990), o conflito surge como parte integrante do espírito da competição esportiva e não como um problema que precisa ser eliminado ou resolvido. Os competidores ao concordarem com as regras e objetivos do jogo estão cientes do conflito inevitável que surgirá a partir de então. Harmonizam-se para conflituar. E conflituam-se pelo prazer de conflituar, nada mais. O esporte é uma luta pelo amor à luta (HELAL, 1990).

$\mathrm{Na}$ verdade, os aspectos de racionalização, secularização com certa tendência à sacralização, organização burocrática, regras fixas e universais, existência de competição, dentre outras características, estão presentes na maioria das modalidades de lutas. Entretanto: seriam as lutas esportes? Será que todas as modalidades de lutas podem ser caracterizadas como esportes?

\section{Caracterização esportiva das lutas}

Todos os esportes possuem certas especificidades que os diferenciam e os distinguem dos demais. Para isso, uma série de regras, normas e critérios surgiram ao longo dos anos permitindo que modalidades até mesmo com origens semelhantes pudessem se tornar distintas.

Com as lutas não foi diferente. Embora com muitas variedades, elas apresentam características semelhantes entre si e diferentes de outras temáticas da cultura corporal. Em termos de práticas esportivas, embora as lutas tenham tido origens diferentes dos esportes, elas apresentam certas especificidades. Porém, primeiramente é preciso enfatizar que existem diversas modalidades de lutas ou artes marciais, cada uma com determinadas características, havendo aspectos em comum e outros diversos em relação a cada uma destas práticas.

Há lutas, por exemplo, que enfocam o embate com armas, enquanto outras privilegiam a luta sem armas. Algumas sociedades criaram formas de lutar a distância, com socos e chutes como, por exemplo, o Krav Maga de Israel, enquanto outras criaram formas de lutar na denominada luta corpo a corpo, sem a distância e sem a utilização de golpes como chutes e socos como, por exemplo, o Judô no Japão. Há ainda a característica de grupos sociais distintos que desenvolveram formas semelhantes de lutar, embora não haja registros de contato entre estes grupos como, por exemplo, duas sociedades que desenvolve- 
ram a luta corpo a corpo, como algumas tribos de índios brasileiros como os povos do alto do Xingu e da tribo Bakairi com o Huka-Huka e os gregos e romanos com o wrestling estilo greco-romano (em ambas as modalidades não é permitido encostar completamente as costas no chão).

Entretanto, mesmo com todo este universo de modalidades, há certas características específicas das lutas, que possibilitam que elas possam ser classificadas dentro de uma mesma categoria na esfera da cultura corporal. Estas semelhanças são o que diferenciam as lutas de outras modalidades esportivas, permitindo que haja certas características em comum entre elas.

O dicionário Luft (2000) define o ato de lutar (do latim luctari) como: "combater/ pelejar, brigar/ disputar, competir/ trabalhar arduamente, esforçar-se, empenhar-se". Já o substantivo luta é definido como "ação de lutar/ qualquer combate corpo a corpo/ guerra, peleja/ antagonismo/ esforço, empenho" (LUFT, 2000, p. 431). Portanto, modalidades esportivas que se assemelhem a esta definição podem ser categorizadas como modalidades esportivas de lutas.

Para os PCNs (1998), as lutas são definidas como "disputas em que $\mathrm{o}(\mathrm{s})$ oponente(s) deve(m) ser subjugado(s), com técnicas e estratégias de desequilíbrio, contusão, imobilização ou exclusão de um determinado espaço na combinação de ações de ataque e defesa" (BRASIL, 1998, p. 70).

Com relação aos conteúdos dos esportes, os PCNs (BRASIL, 1998) consideram-nos como práticas em que são adotadas regras de caráter oficial e competitivo, organizadas em federações regionais, nacionais e internacionais que regulamentam a atuação amadora e a profissional, além de envolverem "condições espaciais e de equipamentos sofisticados como campos, piscinas, bicicletas, pistas, ringues, ginásios, dentre outros" (BRASIL, 1998, p. 70).

Portanto, para os PCNs (BRASIL, 1998), devido às distinções históricas provenientes do fato de possuírem origens diferentes, as lutas são separadas dos esportes e, sendo assim, são caracterizadas como práticas singulares. Entretanto, sua importância é considerada e, por isso, é assegurada que as lutas façam parte da cultura corporal, sendo aplicadas e ressignificadas nas aulas de Educação Física na escola.

Paes (2010) também buscou caracterizações sobre as lutas, apropriando-se de uma definição bem difundida, dividindo as formas de lutar em três tipos: curta, média e longa distância. As lutas de curta 
distância relacionam-se com o agarramento do adversário, as lutas de média distância são aquelas que têm como característica tocar, percutir golpes no adversário (como socos e chutes, por exemplo). Já as lutas de longa distância utilizam-se de implementos e outros materiais como as espadas, por exemplo.

A maior diferenciação entre as lutas e outras modalidades esportivas é o fato do objetivo principal ser o enfrentamento físico direto com um adversário ou oponente. Portanto, ao longo das ações técnicas e táticas, há possibilidades que vão sendo criadas devido a este fator de imprevisibilidade, já que o adversário nunca ficará inerte e responderá às reações de forma inesperada, imprevisível.

O objetivo das lutas envolve superar fisicamente o adversário, utilizando para isso princípios que variam de acordo com cada prática. Elas são práticas individuais, na maioria das vezes, e que requerem a imposição física dos competidores, ou seja, eles se tocam, se agarram, desferem-se chutes, socos, dentre outros golpes visando o objetivo final, que varia conforma cada modalidade. Em nenhuma outra prática esportiva há a possibilidade de impor resistência física contra o adversário de maneira explícita e legal (permitida perante as regras do esporte) visando submetê-lo de diferentes formas.

\section{Lutas: são ou não são esportes?}

As lutas não são apenas práticas esportivas. De acordo com as análises estabelecidas, pode-se considerar que para uma prática ser caracterizada como um esporte ela deve possuir determinadas características. Porém, nem todas as modalidades de lutas enquadramse nestas características. Algumas sofrem constantes resistências de alguns praticantes em relação ao seu enquadramento como esportes.

Há o caso da capoeira que, embora haja algumas formas de sistematização e hierarquização, essas tentativas ainda não foram aceitas por grande parcela de mestres e praticantes. Areias (1984) afirma que a capoeira é uma criação dinâmica e não estática do ser humano, caracterizando-a como: "música, poesia, festa, brincadeira, diversão e, acima de tudo, uma forma de luta, manifestação e expressão do povo, do oprimido e do homem em geral em busca de sobrevivência, liberdade e dignidade" (AREIAS, 1984, p. 8).

Para Areias (1984) alguns mestres de capoeira (sobretudo da capoeira angola) são completamente contra a esportivização dessas práti- 
cas, alegando não ser possível institucionalizá-la. Há outras modalidades também, como o Tai Chi Chuan, por exemplo, considerado, além de uma luta, uma forma de "meditação em movimento" (WIKIPÉDIA, 2010).

Tanto as lutas quanto outras práticas corporais podem ser consideradas como esportes, dependendo das adequações realizadas. Destacam-se como exigências: a utilização de regras universais, a institucionalização de federações e confederações, a presença de autoridade como o árbitro, aparente igualdade de condições entre os competidores, dentre outras.

Da mesma forma, as lutas e outras práticas podem assumir outras características, como as de jogos e brincadeiras se forem praticadas sem atender às exigências dos esportes como, por exemplo: não visar o resultado final propriamente dito, não atender as regras estabelecidas como número de jogadores, uniformes, locais de prática, não depender de órgãos institucionalizados que organizam burocraticamente a modalidade, dentre outras.

$\mathrm{O}$ fato dos esportes e das lutas terem origens distintas, permite que ambos sejam caracterizados separadamente e, dessa forma, lutas e esportes podem ser considerados conteúdos diversificados dentro da esfera da cultura corporal.

Ou seja, as lutas podem ou não ser esportes, de acordo com a organização e regulamentação estabelecida. No contexto da Educação Física escolar, no entanto, é muito mais interessante abordar estes conteúdos de maneira lúdica, promovendo vivências significativas e possibilitando que os alunos possam apropriar-se criticamente destes conteúdos, sendo capazes de conhecê-los, transformá-los e ressignificá-los.

\section{Considerações finais}

Voltando-se à questão central deste texto: por que os autores e propostas da área da Educação Física escolar costumam separar os conteúdos das lutas dos conteúdos dos esportes?

Historicamente, lutas e esportes surgiram em diferentes contextos. O esporte moderno surgiu na Inglaterra no século XIX, com o processo de esportivização de alguns passatempos, conforme afirmam Elias e Dunning (1992) enquanto que as práticas de lutas, seja no oriente ou no ocidente, são práticas inerentes à própria origem dos homens, rece- 
bendo diversas denominações como, por exemplo, práticas de sobrevivência ou práticas utilitárias, dentre outras.

Origens distintas promoveram classificações diferentes. No entanto, apesar de diferentes origens, algumas modalidades de lutas também sofreram o processo de esportivização, como o judô e outras modalidades olímpicas, por exemplo. No âmbito da cultura corporal, o fato de haver a separação das lutas das outras temáticas, como o esporte, pode ser compreendido como uma forma de garantir que elas sejam efetivamente ensinadas nas aulas de Educação Física.

As lutas poderiam estar inseridas dentro dos conteúdos dos esportes, mas dessa forma, elas seriam "diluídas" dentro dos inúmeros outros conteúdos de esporte existentes, sendo aplicadas de maneira superficial, dada a força, tradição e presença de determinados esportes (sobretudo alguns esportes coletivos) nas aulas de Educação Física.

Se as lutas são um dos conteúdos ainda pouco explorados e pouco difundidos nas aulas de Educação Física escolar, pode-se imaginar que se não houvesse a distinção entre lutas e esportes elas praticamente não apareceriam nas aulas de Educação Física na escola, poupando os alunos de vivenciarem essa importante forma de manifestação da cultura corporal.

Outra razão importante que deve levar os autores a proporem a separação das lutas dos esportes é o fato de haver, em grande parte das lutas, características peculiares como a imposição de resistência física explícita contra os adversários.

As lutas são práticas plurais e heterogêneas, com origens distintas do conceito de esporte moderno e de importância histórica, sendo parte integrante da cultura corporal. Não devem ser classificadas apenas como esportes, pois podem possuir outras características, dependendo do contexto na qual estejam inseridas. Há, dessa forma, diversas práticas que ainda não se esportivizaram e nem por isso devem deixar de ser conteúdos da Educação Física escolar, como é o caso do Tai Chi Chuan e da capoeira.

Com relação a essa impossibilidade de compreender as lutas apenas como esporte, destaca-se a frase de Rubem Alves, citado por Marcellino (1989, p. 11): “(...) é da beleza da poesia que nascem os guerreiros. Lutam melhor aqueles em cujos corpos moram os sonhos. Para se lutar não basta ter corpo e saber competentes: é preciso ter alma".

Esta frase ilustra que a questão do lutar pode ser empregada em di- 
versos outros contextos além daqueles que as definem como práticas esportivas. Compreender as lutas enquanto práticas esportivas é questão central para facilitar o entendimento desse fenômeno plural e abrangente, porém, deve-se destacar que o ato de lutar pode transcender a visão esportiva destas práticas, até mesmo por possuírem origens históricas diferentes. Entretanto, independente de serem classificadas ou não como modalidades esportivas, as lutas possuem a sua importância e devem ser ensinadas aos alunos nas aulas de Educação Física escolar, possibilitando que eles se apropriem deste importante conteúdo da cultura corporal.

The separation of the contents "fights" of "sports" in Physical Education Classes: necessity or tradition?

\begin{abstract}
A lot of curriculum proposals present the division between fights and sports contents. However, isn't fights sports too? Why do they separate these contents? The objective of this study was to discuss about the reasons why some proposals and some authors separate the fights contents of the sports contents in body culture conception. For this, we analyzed, through a review of literature, the concepts of fights and sports in some curriculum proposals and some authors in the field of Physical Education. We conclude that the separation occurs for different reasons, and it may offer a means of ensuring that these contents could be applied in Physical Education classes.
\end{abstract}

Keywords: Fights - Martial Arts - Sports - Physical Education Classes

Separación de los contenidos de la "luchas" y el "deportes" en la escuela de Educación Física: ¿necessidad o tradición?

\title{
Resumen
}

Muchas propuestas curriculares muestran la división entre los contenidos de las luchas y los deportes. Pero las luchas no son deportes también? Por qué hay esta separación? El objetivo de este estudio era examinar las posibles razones de la separación de contenidos de las luchas y deportes en el alcance de la cultura física. Para ello, hemos tratado de analizar a través de uma revisión de la literatura, los conceptos de lucha y los deportes presentes en los currículos, y algunos autores en el ámbito de la educación física. Se concluye que la separación se produce por diferentes razones. Así, separar las luchas de los deportes es una manera de asegurar que estos contenidos se aplican en las clases de educación física en la escuela.

Palabras clave: Luchas - Artes Marciales - Deportes - Educación Física en la Escuela 


\section{Referências}

AREIAS, A. O que é capoeira? São Paulo: Brasiliense, 1984.

BETTI, M. Educação Física escolar: ensino e pesquisa ação. Ijuí: Unijuí, 2009.

BRASIL. Ministério da Educação e do Desporto. Secretaria de Educação Fundamental. Parâmetros Curriculares Nacionais: Educação Física, $3^{\circ}$ e $4^{\circ}$ ciclos. Brasília, 1998. v.7.b.

CARREIRO, E. A. Lutas. In: DARIDO, S. C.; RANGEL, I. C. A. Educação Física na escola: Implicações para a prática pedagógica. Rio de Janeiro: Guanabara Koogan, 2005.

CORREIA, W. R.; FRANCHINI, E. Produção acadêmica em lutas, artes marciais e esportes de combate. Motriz. Rio Claro, v. 16, n. 1, p. $01-09,2010$.

DA COSTA, L. Atlas do esporte no Brasil. Rio de Janeiro: CONFEF, 2006. Disponível em: <www.atlasesportebrasil.org.br/textos/360.pdf>. Acesso em: 08 mai. 2010.

DARIDO, S. C.; RANGEL, I. C. A. Educação Física na escola: implicações para a prática pedagógica. Rio de Janeiro: Guanabara Koogan, 2005.

DARIDO, S. C.; SOUZA JÚNIOR, O. M. Para ensinar Educação Física: possibilidades de intervenção na escola. Campinas: Papirus, 2007.

DEL'VECCHIO, F. B.; FRANCHINI, E. Lutas, Artes Marciais e Esportes de Combate: Possibilidades, Experiências e Abordagens no Currículo da Educação Física. In: SOUZA NETO, S.; HUNGER, D. Formação profissional em Educação Física: estudos e pesquisas. Rio Claro: Biblioética, 2006.

ELIAS, N. DUNNING, E. A busca da excitação. Lisboa: Difel, 1992.

HELAL, R. O que é sociologia do esporte. São Paulo: Brasiliense, 1990.

HUIZINGA, J. Homo ludens: o jogo como elemento da cultura. 4. ed. São Paulo: Perspectiva, 1993. 
LUFT, C. P. Minidicionário Luft da Língua Portuguesa. 20. ed. São Paulo: Ática, 2000.

MARCELlinO, N. C. Pedagogia da animação. Campinas: Papirus, 1989.

RAMOS, J. J. Os exercícios físicos na história e na arte. São Paulo: Ibrasa, 1982.

RIO GRANDE DO SUL. Secretaria de Estado de Educação. Referenciais Curriculares do Estado do Rio Grande do Sul: Linguagens, Códigos e suas Tecnologias. Porto Alegre, 2009. v. 2.

RUFINO, L. G. B.; DARIDO, S. C. O jiu jitsu brasileiro nas três dimensões dos conteúdos nas aulas de educação física escolar. In: IV Colóquio de Pesquisa Qualitativa em Motricidade Humana: as lutas no contexto da motricidade / III Simpósio sobre o Ensino de Graduação em Educação Física: 15 anos do Curso de Educação Física da UFSCar / V Shoto Workshop, 4, 2009, São Carlos. Anais... São Carlos: UFSCar, 2009. CD ROM.

SÃO PAULO. Secretaria da Educação do Estado de São Paulo. Proposta Curricular do Estado de São Paulo: Educação Física, Ensino Fundamental ciclo II e Ensino Médio. São Paulo, 2008.

SOARES, C. L. Educação Física escolar: conhecimento e especificidade. Revista Paulista de Educação Física, p. 6 - 12, 1996. Suplemento 2 .

SOARES, C. L..; TAFFAREL, C. N. Z.; VARJAL, E.; CASTELLANI FILHO,L.; ESCOBAR, M. O.; BRACHT, V. Metodologia do ensino da educação física. São Paulo: Cortez, 1992.

PAES, R. R. Desenvolvimento das aulas de lutas: da compreensão teórica aos procedimentos práticos. In: BREDA, M.; GALATTI, L.; SCAGLIA, J. A.; PAES, R. R. Pedagogia do esporte aplicada às lutas. São Paulo: Phorte, 2010.

VIRGILIO, S. A arte do judô. Porto Alegre: Rígel, 1994.

WIKIPÉDIA, a enciclopédia livre. Tai Chi Chuan. Disponível em: $<$ http://pt.wikipedia.org/wiki/Tai_Chi_Chuan>. Acesso em: 12 mai. 2010. 
Recebido em: 20/10/2010

Revisado em: 105/03/2011

Aprovado em: 10/03/2011

\section{Endereço para correspondência}

gustavo_rufino_6@hotmail.com

Luiz Gustavo Bonatto Rufino

Universidade Estadual Paulista Júlio de Mesquita Filho

Departamento de Educação Física.

Av. 24 A, No 1515

Bela Vista

13506-000 - Rio Claro, SP - Brasil 